\title{
Association of Television Watching Practices of Mothers on Overweight and Obesity of Their Under-5 Offspring in Urban Bangladesh
}

\author{
Jui Das', Sumon Kumar Das',2, Shahnawaz Ahmed ${ }^{1}$, Mohammod Jobayer Chisti', \\ Mohammad Habibur Rahman Sarker ${ }^{1}$, Fahmida Dil Farzana ${ }^{1}$, Farzana Ferdous ${ }^{1,3}$, \\ Mohammad Abdul Malek' ${ }^{1}$ Aminur Rahman'1, Abu Syed Golam Faruque ${ }^{1 *}$, \\ Abdullah Al Mamun² \\ ${ }^{1}$ International Centre for Diarrhoeal Disease Research, Bangladesh (icddr,b), Dhaka, Bangladesh \\ ${ }^{2}$ School of Population Health, The University of Queensland, Brisbane, Australia \\ ${ }^{3}$ Department of Clinical Trial and Clinical Epidemiology, Graduate School of Comprehensive Human Sciences, \\ University of Tsukuba, Tsukuba, Japan \\ Email: jui das26@yahoo.com, jui.das@icddrb.org, sumon@icddrb.org, sumon.das@uqconnect.edu.au, \\ shahnawz@icddrb.org, chisti@icddrb.org, habibur.rahman@icddrb.org, fahmidaf@icddrb.org, \\ farzanaf@icddrb.org, mamalek@icddrb.org, draminur@icddrb.org, gfaruque@icddrb.org, \\ mamun@sph.uq.edu.au
}

Received 16 August 2014; revised 6 September 2014; accepted 12 September 2014

Copyright (C) 2014 by authors and Scientific Research Publishing Inc.

This work is licensed under the Creative Commons Attribution International License (CC BY). http://creativecommons.org/licenses/by/4.0/

c. (i) Open Access

\section{Abstract}

Childhood overweight and obesity, is an emerging public health concern in developing countries like Bangladesh. However, regular television watching by child's mother and its impact on excess weight gain or overweight and obesity to their offspring is not reported elsewhere. The aim of the present analysis was to determine the socio-demographic characteristics among overweight and obese children based on those mothers who watch television regularly and compare this finding with malnourished and well-nourished under-5 children. A total of 20,800 under-5 children were enrolled during 1996 to 2012 in the Diarrheal Disease Surveillance System (DDSS) of Dhaka Hospital of International Centre for Diarrhoeal Disease Research, Bangladesh (icddr,b). Mean weight-for-age $z$-score $(-1.61$ vs. -2.30 ; mean difference: $-0.69 ; p<0.001)$, height-for-age z-score $(-1.42$ vs. $-1.99 ;-0.57 ;<0.001)$, weight-for-height $z$-score $(-1.59$ vs. $-1.07 ;-0.53$; $<0.001)$, BMI-for-age z-score $(-1.09$ vs. $-1.61,-0.52 ;<0.001)$ differed significantly between the children whose mother did and did not watch television regularly. Under-5 children whose mother watched television regularly $(2 \%)$ compared to those who did not $(1 \%)$, had 2.28 [(95\% 
CI-1.61 - 3.24) $p<0.001$ ] times increased odds of being overweight and obese. Television watching of mothers is associated with childhood overweight and obesity and is one of the most public health concerns in Bangladesh. These changes may be in part of better socio-economic condition, changes in life style behaviour and dietary pattern.

\section{Keywords}

\section{Childhood Overweight and Obesity, Mother's Watching of Television, Urban, Bangladesh}

\section{Introduction}

The double burden of under nutrition and over nutrition has already been determined as global health concern [1] [2]. Prevalence of childhood obesity has been increased sharply during the past few decades [3] [4]. This number has become double in the last two or three decades in the developed as well as developing region [5].

Overweight and obesity, an emerging childhood malnutrition, is a growing public health concern in developing countries like Bangladesh affecting all age groups as well [6] [7]. Obesity and its consequences are among the leading causes of deaths and it has been increasing sharply during the past few decades [4] [7]. Several socio-economic and behavioural factors which are associated with childhood overweight and obesity include the relentless access to mass media especially watching television [8] [9].

Researcher had found that watching television has direct relation with childhood overweight and obesity [10]-[13]; however, most of them were from developing context with few exceptions, and there is lack of evidence based information especially among Bangladeshi children [14]. The International Centre for Diarrhoeal Disease Research, Bangladesh (icddr,b) maintains a round the clock Diarrheal Disease Surveillance System (DDSS) where children under-5 year with diarrhea were enrolled irrespective of sex and socio-economic status [15]. Information on watching television regularly was collected as a part of socio-demographic indicators. Taking the advantage of this long standing data-base, the present sub-group analysis aimed to determine the socio-demographic characteristics among overweight and obese children whose mother watched television regularly and compare this findings with that of well-nourished and malnourished under-5 children.

\section{Method}

\subsection{Study Population, Site and Source of Data}

The study was conducted among under five children visiting the Dhaka Hospital of icddr,b, located in Dhaka, the capital city of Bangladesh which provides cost free care and treatment to about 140,000 patients each year. The DDSS of icddr,b has been established since 1979, to collect longitudinal data on the hospital's patient populations. The DDSS currently collects information on clinical, epidemiological and demographic characteristics including watching television, nutritional status of infants and young children. A trained research assistant interviewed care givers of children.

The DDSS recently explored a dramatic increase in overweight and obese under-5 children [7] [15]. Due to limitation of data on impact of regular watching of television by mother on childhood overweight and obesity, we evaluated the same from 1996-2012 by observing 20,800 under-5 children.

Detailed socio-demographic information including mother's television practice (watching television regularly or not) were also collected. Child's nutritional indices (weight and height) were measured following standard guideline [16]; and overweight and obesity were defined according to WHO guidelines using BMI-for-age zscore $(\geq+2.00 \mathrm{SD})[17]$.

\subsection{Data Analysis and Sampling Frame}

Data analysis was done using Statistical Package for Social Sciences (SPSS) for Windows (Version 15.2; Chicago, IL) and Epi Info (Version 6.0, USD, Stone Mountain, GA). Data were first categorized into two groups 1) watched TV $(=1) ; 2)$ did not watch TV $(=0)$ and compared their socio-demographic information, clinical char- 
acteristic and pathogen responsible for diarrhea by Chi-square test and a probability of $<0.05$ (Type I error) was considered as statistically significant. Proportion of mother watched TV was analyzed by nutritional status (overweight and obese, well-nourished, and malnourished). Then in-depth analysis was performed assuming the proportion of overweight and obese was higher among children whose mother watched TV regularly. Here data was categorized into 3 quarters among TV watching group as 1) overweight and obese, 2) well-nourished, and 3) malnourished and compared by applying both descriptive and analytical methods. Overweight and obese was considered as risk group while well-nourished and malnourished as referral categories to determine the predictors of overweight and obese among children whose mother watched TV on regular basis.

\subsection{Ethical Consideration}

This activity was approved by the Research and Ethical Review Committees of icddr,b and the detail has been reported elsewhere [18].

\section{Results}

Mean weight-for-age $\mathrm{z}$-score $(-1.61$ vs. -2.30 ; mean difference: $-0.69 ; \mathrm{p}<0.001)$, height-for-age $\mathrm{z}$-score ( -1.42 vs. -1.99 ; mean difference: -0.57 ; $\mathrm{p}<0.001)$, weight-for-height $\mathrm{z}$-score $(-1.59$ vs. -1.07 ; mean difference: -0.53 ; $\mathrm{p}<0.001)$, and BMI-for-age z-score $(-1.09$ vs. -1.61 , mean difference: $-0.52 ; \mathrm{p}<0.001)$ differed significantly between the children whose mother did and did not watch television regularly (data not shown). Under-5 children whose mother watched television regularly $(2 \% ; n=297)$ compared to those who did not $(1 \%$; $n$ = 39), had 2.28 [(95\% CI-1.61-3.24) p < 0.001] times increased odds of being overweight and obese (Table 1).

Among under-5 children whose mother watched television regularly; higher proportion of those mothers were literate, had smaller family size, living in a non slum residential area, had higher monthly family income (>100 USD), used sanitary toilet, used boiled water for drinking compared to non-watching group (Table 2).

Table 1. Different nutritional status among under-5 children on the basis of mother's watching television (TV) regularly.

\begin{tabular}{cccc}
\hline Indicators & Watched TV; $\mathbf{n}=\mathbf{1 6 , 0 4 3}(\mathbf{\%})$ & Did not-watch TV; $\mathbf{n}=\mathbf{4 7 5 7}(\mathbf{\%})$ & OR (95\% CI) $\mathbf{p}$-value \\
\hline Overweight and obese & $297(2)$ & $39(1)$ & $2.28(1.61,3.24)<0.001$ \\
Well-nourished & $8115(50)$ & $1518(32)$ & $2.18(2.04,2.34)<0.001$ \\
Malnourished & $7631(48)$ & $3200(67)$ & $0.44(0.41,0.47)<0.001$ \\
\hline
\end{tabular}

Table 2. Socio-demographic characteristics among under-5 children whose mother watched TV regularly.

\begin{tabular}{cccc}
\hline Indicators & Watched TV; $\mathbf{n}=\mathbf{1 6 , 0 4 3}(\mathbf{\%})$ & Did not watch TV; $\mathbf{n}=\mathbf{4 7 5 7}(\mathbf{\%})$ & OR (95\% CI) p-value \\
\hline Age & & & \\
$24-59$ months & $2284(14)$ & $857(18)$ & $0.76(0.69,0.82)<0.001$ \\
$12-23$ months & $4408(28)$ & $1355(29)$ & $0.95(0.88,1.02) 0.178$ \\
$0-11$ months & $9351(58)$ & $2545(54)$ & $1.21(1.14,1.30)<0.001$ \\
Male & $9858(61)$ & $2952(62)$ & $0.97(0.91,1.04) 0.458$ \\
Maternal literacy & $11788(74)$ & $2076(44)$ & $3.58(3.34,3.83)<0.001$ \\
Family size (<5) & $10435(65)$ & $3200(67)$ & $0.91(0.84,0.97) 0.004$ \\
Residence (non-slum) & $15000(93)$ & $3906(72)$ & $3.14(2.85,3.46)<0.001$ \\
Monthly income (>100 USD) & $8348(52)$ & $1087(23)$ & $3.66(3.40,3.95)<0.001$ \\
Sanitary toilet & $11131(69)$ & $2113(44)$ & $2.84(2.65,3.03)<0.001$ \\
Drink boiled water & $5978(37)$ & $750(16)$ & $3.17(2.91,3.46)<0.001$ \\
\hline
\end{tabular}


While we compared within the TV watching groups, overweight and obese were different in socio-economic aspects from their counterpart. For example, higher proportion of mothers belonging to overweight and obese children were literate, had higher monthly income (>100 USD), used sanitary toilet, and boiled drinking water compared to well-nourished and malnourished children (Table 3).

In multivariate analysis, children aged 24 - 59 months, male children, literate mother and higher monthly family income (>100 USD) were significantly associated with overweight and obese children whose mother watched TV regularly when well-nourished was considered as referral group (Table 4(a)). On the other hand, considering malnourished as referral group, overweight and obese was significantly associated with maternal literacy and higher monthly family income (Table 4(b)).

\section{Discussion}

Watching television by the mothers of young children has strong association with excess weight gain with subsequent ramification to overweight and obesity in late childhood [12], and persists till their adolescent age and adulthood. However, watching of television regularly by mothers also has significant impact on excess weight gain or overweight and obesity to their offspring - that is an interesting finding and was not reported elsewhere. It is difficult to explain such association with childhood overweight and obesity based on the present cross-sectional surveillance system and therefore does not allow for any causal inference of children with diarrhea due to lack of life-style and behavioural information. Rapid and unplanned urbanization drastically reduces open room for playing condition which divert them towards idle indoor games especially video games or watching television, resulting in their less catabolic activities. Mothers, those who watch television during leisure time, their kids potentially accompany them probably with changes in their feeding practices that may include highly dense fatty meal. Most of the cases, household with television is from well-off socio-economic status in whom childhood overweight and obesity has been reported [19] [20]. Our present finding, urges further exploration of public health interest to determine comprehensive impact of the life style and behaviour of mothers on overweight and obesity of their offspring's.

\section{Limitations}

This study was conducted among children attending a large diarrheal disease health facility and may not be representative of for general population. Strengths of our study include long time period for data collection, and use of large, systematic sample and unbiased sampling of the surveillance system.

Table 3. Socio-demographic characteristics of under-5 children by different nutritional status whose mother watched TV regularly.

\begin{tabular}{|c|c|c|c|c|c|}
\hline Indicators & $\begin{array}{l}\text { Overweight } \\
\mathrm{n}=297 \text { (\%) }\end{array}$ & $\begin{array}{l}\text { Well nourished } \\
\mathbf{n}=\mathbf{8 1 1 5}(\%)\end{array}$ & $\mathrm{OR}^{1}(95 \% \mathrm{CI}) \mathrm{p}$-value & $\begin{array}{c}\text { Malnourished } \\
\mathrm{n}=7631(\%)\end{array}$ & $\mathrm{OR}^{2}(95 \% \mathrm{CI}) \mathrm{p}$-value \\
\hline \multicolumn{6}{|l|}{ Age } \\
\hline 24 - 59 months & $45(15)$ & $817(10)$ & $1.60(1.14,2.23) 0.006$ & $1422(19)$ & $0.78(0.56,1.09) 0.149$ \\
\hline 12 - 23 months & $89(30)$ & $2285(28)$ & $1.09(0.84,1.42) 0.538$ & $2034(27)$ & $1.18(0.91,1.53) 0.230$ \\
\hline 0 - 11 months & $163(55)$ & $5013(62)$ & $0.75(0.59,0.96) 0.019$ & $4175(55)$ & $1.01(0.79,1.28) 0.998$ \\
\hline Male & $209(74)$ & 4824 (59) & $1.62(1.25,2.10)<0.001$ & $4825(63)$ & $1.38(1.06,1.79) 0.014$ \\
\hline Maternal literacy & $270(91)$ & $6767(83)$ & $1.99(1.31,1.49)<0.001$ & $4751(62)$ & $6.06(4.01,9.22)<0.001$ \\
\hline Family size $(<5)$ & $201(68)$ & $5058(62)$ & $1.27(0.98,1.963) 0.070$ & $5176(68)$ & $0.99(0.77,1.28) 0.993$ \\
\hline Residence (non-slum) & 293 (99) & $7842(97)$ & $2.54(0.91,8.05) 0.081$ & $6825(90)$ & $8.16(2.93,25.74)<0.001$ \\
\hline Monthly income (>100 USD) & $231(78)$ & $5139(63)$ & $2.03(1.52,2.70)<0.001$ & 2978 (39) & $5.47(4.11,7.29)<0.001$ \\
\hline Sanitary toilet & $251(85)$ & $6078(75)$ & $1.83(1.32,2.55) 0.002$ & $4802(63)$ & $3.21(2.32,4.48)<0.001$ \\
\hline Drink boiled water & $154(52)$ & 3487 (43) & $1.43(1.13,1.81) 0.002$ & $2337(31)$ & $2.24(1.92,3.10)<0.001$ \\
\hline
\end{tabular}

Overweight and obese, and well-nourished $=\mathrm{OR}^{1}(95 \% \mathrm{CI}) \mathrm{p}$-value; Overweight and obese, and Malnourished $=\mathrm{OR}^{2}(95 \% \mathrm{CI}) \mathrm{p}$-value. 
Table 4. (a, b) Factors associated with children overweight and obese whose mother watched TV regularly.

(a)

\begin{tabular}{ccc}
\hline Indicators & OR $\mathbf{( 9 5 \% \mathbf { C I } )}$ & p-Value \\
\hline Age & & \\
$24-59$ months & $1.67(1.22,2.29)$ & $<0.001$ \\
$12-23$ months & $1.06(0.86,1.42)$ & 0.430 \\
$0-11$ months & 1 & \\
Male & $1.71(1.35,2.17)$ & $<0.001$ \\
Maternal literacy & $1.47(1.04,2.07)$ & 0.030 \\
Monthly income (>100 USD) & $1.56(1.20,2.03)$ & $<0.001$ \\
Sanitary toilet & $1.34(0.98,1.83)$ & 0.071 \\
Drink boiled water & $1.04(0.81,1.32)$ & 0.782 \\
\hline
\end{tabular}

Dependent variable: overweight and obese $=1$, well-nourished $=0$.

(b)

\begin{tabular}{ccc}
\hline Indicators & OR $(\mathbf{9 5} \% \mathbf{C I})$ & p-Value \\
\hline Male & $1.42(1.12,1.81)$ & 0.004 \\
Maternal literacy & $2.89(2.04,4.07)$ & $<0.001$ \\
Residence (non-slum) & $2.50(1.16,5.41)$ & 0.020 \\
Monthly income (>100 USD) & $3.16(2.44,4.09)$ & $<0.001$ \\
Sanitary toilet & $1.46(1.08,1.98)$ & 0.014 \\
Drink boiled water & $1.43(1.13,1.81)$ & 0.003 \\
\hline
\end{tabular}

Dependent variable: overweight and obese $=1$, malnourished $=0$.

\section{Conclusion}

Our study demonstrated that, mothers' television watching is associated with childhood overweight and obesity. However, recently in Bangladesh overweight and obesity is gaining attention under public health issues. These changes may be the consequences of better socio-economic condition, modified life style behaviour and dietary pattern as well. The findings of present study may be a snap shot of the hidden underlying burden and thus enhance further researches especially on daily behaviour on watching television by the mother's of young children becoming overweight and obese.

\section{Conflict of Interest}

There is no potent conflict of interest to declare. All authors confirmed that there is no professional affiliation, financial agreement or other involvement with any company whose product figures prominently in the submitted manuscript.

\section{Authors' Contributions}

JD, SKD, SH, MJC, MAM, ASGF, AAM—-have made substantial contributions to conception and design, or acquisition of data, or analysis and interpretation of data; JD, SKD, MJC-have been involved in drafting the manuscript; JD, SKD, SH, MJC, MAM, AR, ASGF, AAM, MHRS, FDF, FF revised it critically for important intellectual content; ASGF, SKD-have given final approval of the version to be published. Each author has participated sufficiently in the work to take public responsibility for appropriate portions of the content. All authors 
have read and approved the final manuscript.

\section{Acknowledgements}

icddr,b acknowledges with gratitude the commitment of the Government of the People's Republic of Bangladesh to it's research efforts who funded the study through IHP-HNPRP. icddr,b is also thankful to the Governments of Australia, Bangladesh, Canada, Sweden and the United Kingdom for providing core/unrestricted support.

\section{References}

[1] Ly, K.A., Ton, T.G., Ngo, Q.V., Vo, T.T. and Fitzpatrick, A.L. (2013) Double Burden: A Cross-Sectional Survey Assessing Factors Associated with Underweight and Overweight Status in Danang, Vietnam. BMC Public Health, $13,35$. http://dx.doi.org/10.1186/1471-2458-13-35

[2] Black, R.E., Victora, C.G., Walker, S.P., Bhutta, Z.A., Christian, P., de Onis, M., Ezzati, M., Grantham-McGregor, S., Katz, J., Martorell, R. and Uauy, R. (2013) Maternal and Child Undernutrition and Overweight in Low-Income and Middle-Income Countries. Lancet, 382, 427-451. http://dx.doi.org/10.1016/S0140-6736(13)60937-X

[3] Shafique, S., Akhter, N., Stallkamp, G., de Pee, S., Panagides, D. and Bloem, M.W. (2007) Trends of under- and Overweight among Rural and Urban Poor Women Indicate the Double Burden of Malnutrition in Bangladesh. International Journal of Epidemiology, 36, 449-457. http://dx.doi.org/10.1093/ije/dyl306

[4] Kelly, T., Yang, W., Chen, C.S., Reynolds, K. and He, J. (2008) Global Burden of Obesity in 2005 and Projections to 2030. International Journal of Obesity (London), 32, 1431-1437. http://dx.doi.org/10.1038/ijo.2008.102

[5] Van Hook, J., Altman, C.E. and Balistreri, K.S. (2013) Global Patterns in Overweight among Children and Mothers in Less Developed Countries. Public Health Nutrition, 16, 573-581. http://dx.doi.org/10.1017/S1368980012001164

[6] Bhuiyan, M.U., Zaman, S. and Ahmed, T. (2013) Risk Factors Associated with Overweight and Obesity among Urban School Children and Adolescents in Bangladesh: A Case-Control Study. BMC Pediatrics, 13, 72.

[7] Das, S.K., Chisti, M.J., Huq, S., Malek, M.A., Vanderlee, L., Salam, M.A., Ahmed, T., Faruque, A.S.G. and Mamun, A.A. (2013) Changing Trend of Overweight and Obesity and Their Associatied Factors in an Urban Population of Bangladesh. Food and Nutrition Sciences, 4, 678-689.

[8] Bingham, D.D., Varela, S., Maria, I., Ferrao, M.M., Gama, A., Mourão, I.M., Nogueira, H., Marques, R.V. and Padez, C. (2013) Socio-Demographic and Behavioral Risk Factors Associated with the High Prevalence of Overweight and Obesity in Portuguese Children. American Journal of Human Biology, 25, 733-742.

[9] El-kholy, T.A., Hassanen, N.H.M. and Hassan, R.M. (2012) Demographic, Socio-Economic Factors and Physical Activity Affecting the Nutritional Status of Young Children under Five Years. Life Science Journal, 9, 3604-3614.

[10] Dennison, B.A., Erb, T.A. and Jenkins, P.L. (2002) Television Viewing and Television in Bedroom Associated with Overweight Risk among Low-Income Preschool Children. Pediatrics, 109, 1028-1035.

http://dx.doi.org/10.1542/peds.109.6.1028

[11] Lissner, L., Lanfer, A., Gwozdz, W., Olafsdottir, S., Eiben, G., Moreno, L.A., Santaliestra-Pasias, A.M., Kovacs, E., Barba, G., Loit, H.-M., Kourides, Y., Pala, V., Pohlabeln, H., De Henauw, S., Buchecker, K., Ahrens, W. and Reisch, L. (2012) Television Habits in Relation to Overweight, Diet and Taste Preferences in European Children: The IDEFICS Study. European Journal of Epidemiology, 27, 705-715. http://dx.doi.org/10.1007/s10654-012-9718-2

[12] Mamun, A.A., O’Callaghan, M.J., Williams, G. and Najman, J.M. (2013) Television Watching from Adolescence to Adulthood and Its Association with BMI, Waist Circumference, Waist-to-Hip Ratio and Obesity: A Longitudinal Study. Public Health Nutrition, 16, 54-64. http://dx.doi.org/10.1017/S1368980012002832

[13] Perez, A., Hoelscher, D.M., Springer, A.E., Brown, H.S., Barroso, C.S., Kelder, S.H. and Castrucci, B.C. (2011) Physical Activity, Watching Television and the Risk of Obesity in Students, Texas, 2004-2005. Preventing Chronic Disease, 8, A61.

[14] Al-Ghamdi, S.H. (2013) The Association between Watching Television and Obesity in Children of School-Age in Saudi Arabia. Journal of Family and Community Medicine, 20, 83-89. http://dx.doi.org/10.4103/2230-8229.114767

[15] Das, S.K., Chisti, M.J., Huq, S., Malek, M.A., Vanderlee, L., Kaur, G., Salam, M.A., Ahmed, T., Faruque, A.S.G. and Mamun, A.A. (2013) Clinical Characteristics, Etiology and Antimicrobial Susceptibility among Overweight and Obese Individuals with Diarrhea: Observed at a Large Diarrheal Disease Hospital, Bangladesh. PLoS ONE, 8, e70402. http://dx.doi.org/10.1371/journal.pone.0070402

[16] WHO (2013) The WHO Child Growth Standards. http://www.who.int/childgrowth/en/

[17] NOO (2011) A Simple Guide to Classifying Body Mass Index in Children. National Obesity Observatory, on Behalf of 
Public Health Observatories in England.

[18] Stoll, B.J., Glass, R.I., Huq, M.I., Khan, M.U., Holt, J.E. and Banu, H. (1982) Surveillance of Patients Attending a Diarrhoeal Disease Hospital in Bangladesh. British Medical Journal, 285, 1185-1188.

[19] Thibault, H., Contrand, B., Saubusse, E., Baine, M. and Maurice-Tison, S. (2010) Risk Factors for Overweight and Obesity in French Adolescents: Physical Activity, Sedentary Behaviour and Parental Characteristics. Nutrition, 26, 192-200. http://dx.doi.org/10.1016/j.nut.2009.03.015

[20] Danielzik, S., Czerwinski-Mast, M., Langnase, K., Dilba, B. and Muller, M.J. (2004) Parental Overweight, Socioeconomic Status and High Birth Weight are the Major Determinants of Overweight and Obesity in 5-7 Year-Old Children: Baseline Data of the Kiel Obesity Prevention Study (KOPS). International Journal of Obesity and Related Metabolic Disorders, 28, 1494-1502.

\section{List of Abbreviations}

BMI: Body Mass Index

CI: Confidence Interval

DDSS: Diarrheal Disease Surveillance System

icddr,b: International Centre for Diarrhoeal Disease Research, Bangladesh

SPSS: Statistical Package for Social Sciences

SD: Standard Deviation

USD: United States Dollar

WHO: World Health Organization 
Scientific Research Publishing (SCIRP) is one of the largest Open Access journal publishers. It is currently publishing more than 200 open access, online, peer-reviewed journals covering a wide range of academic disciplines. SCIRP serves the worldwide academic communities and contributes to the progress and application of science with its publication.

Other selected journals from SCIRP are listed as below. Submit your manuscript to us via either submit@scirp.org or Online Submission Portal.
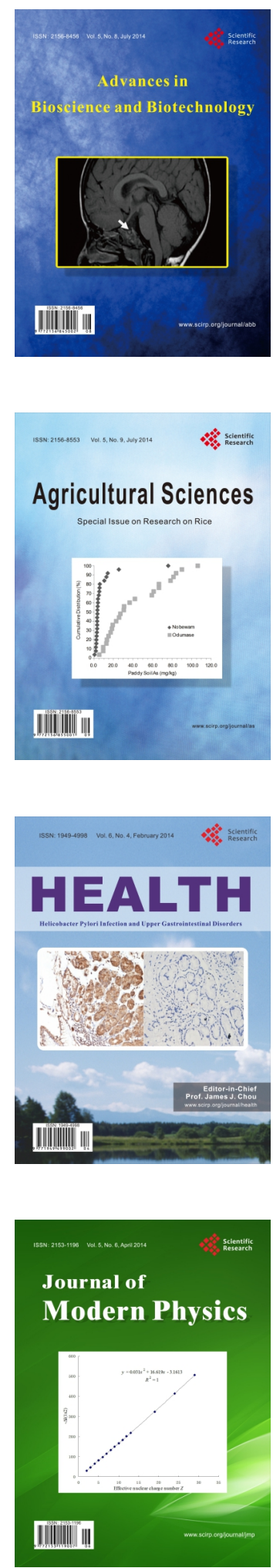
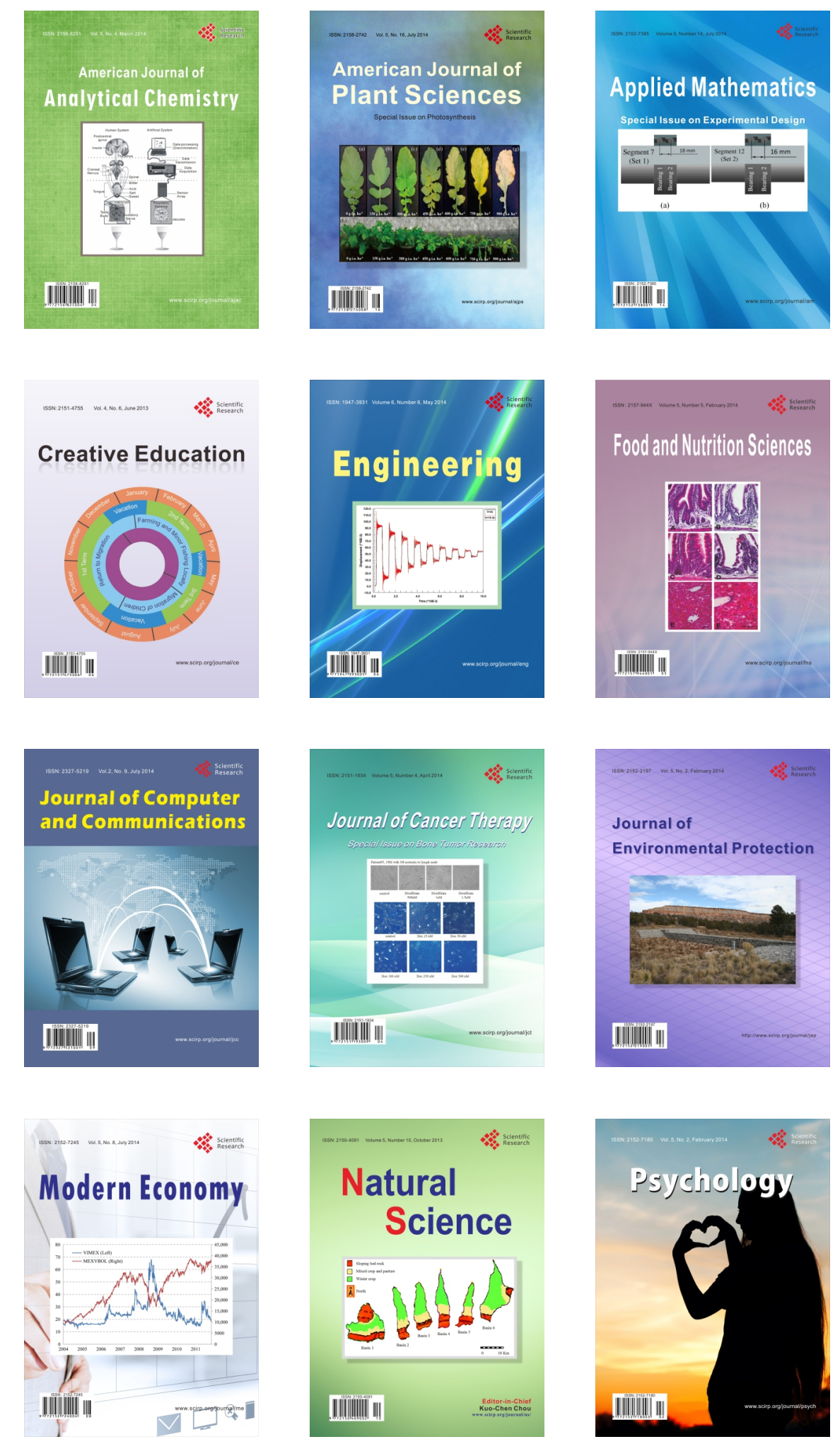